\title{
Prevalence and risk factors of parasitic diseases among Saudi children
}

\author{
An updated review
}

Jamila S. Al-Malki, MS, PhD.

\begin{abstract}
عدوى الطفيليات المعوية هي مشكلة صحية عالمية آخذة في الانخفاض.

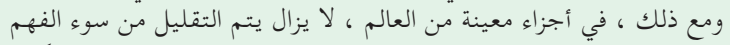

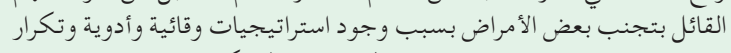

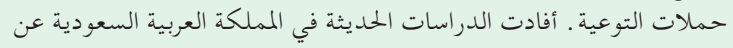

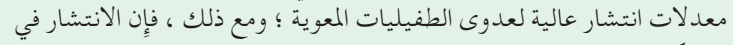

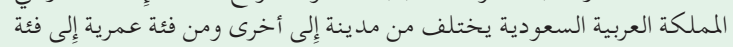

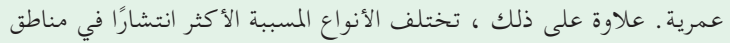

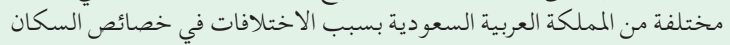

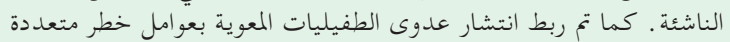

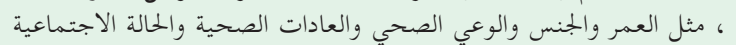

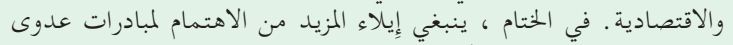

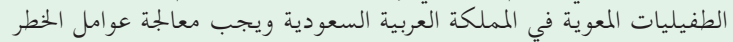

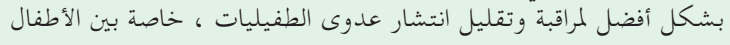
الأصغر سنًا.
\end{abstract}

Intestinal parasite infection (IPI) is a declining global health problem. However, in certain parts of the world, the misconception that certain diseases are avoided owing to the existence of prevention strategies, medication and the frequency of awareness campaigns remains underestimated. Recent studies in Saudi Arabia have reported high prevalence rates for IPI; however, the prevalence in Saudi Arabia varies from city to city and from age group to age group. Moreover, the most prevalent causative species vary in different areas of Saudi Arabia due to differences in the characteristics of emerging populations. The prevalence of IPI has also been correlated with multiple risk factors, such as age, gender, health awareness, health habits and socioeconomic status. Therefore, more attention should be given to IPIs in Saudi Arabia and the risk factors should be better addressed to monitor and reduce the spread of parasite infections, particularly among younger children.

Keywords: Prevalence, intestinal parasite infection, Saudi children, age, gender
Saudi Med J 2021; Vol. 42 (6): 612-619

doi: 10.15537/smj.2021.42.6.20200784

From the Department of Biology, Collage of Science, Taif University, Taif, Kingdom of Saudi Arabia.

Address correspondence and reprint request to: Dr. Jamila S. Al-Malki, Department of Biology, Collage of Science, Taif University, Taif, Kingdom of Saudi Arabia.E-mail: J.ali@tu.edu.sa

ORCID ID: https://orcid.org/0000-0002-9140-5649

A ccording to the World Health Organization (WHO), foodborne illnesses are a significant concern worldwide. ${ }^{1}$ Precise epidemiological analyses are crucial to better understand the burden of foodborne diseases for determining the effects of food security interventions and advising decision-makers on the costeffective use of sometimes restricted resources. However, to date, there is a lack of reliable and clear global knowledge on most foodborne agents or pathogens. ${ }^{2}$

Intestinal parasites are the largest source of chronic infectious illness worldwide, with reports that at least one-fifth of the world's population is contaminated. ${ }^{3}$ Intestinal parasites are a significant health problem in developed countries. Approximately $80 \%$ of all the deaths that occur annually in these countries are due to infection-related diseases and parasites; protozoa and helminthic parasitic infections, which are types of intestinal parasite infections (IPIs), affect 3.5 million people globally, most of them children. ${ }^{4}$

The occurrence of these parasites is generally associated with unsanitary living conditions. In some countries, the existence of more intestinal parasites was connected to disease, particularly in children. ${ }^{5}$ In Saudi Arabia, an unusually high prevalence rate of parasites has been reported, making IPI a common health problem $^{6}$ that impacts the country's rapid economic growth, despite an overall improvement in health care. 
The number of people worldwide with a specific link to parasite-infected children has been thought to increase. ${ }^{3}$ Even with the overall increase in sanitation and the quality of life in Saudi Arabia, intestinal parasites are common in the country. ${ }^{3}$

This study aimed to an updated summary of recent evidence regarding the prevalence and risk factors of IPI and the causative organisms and features of these infections.

Prevalence of IPIs in the Kingdom of Saudi Arabia (KSA). Previous studies have reported that the prevalence rates of IPIs in the KSA range from $9.5 \%$ to $47.4 \%$ in children that are either symptomatic or asymptomatic. ${ }^{3,6}$ In Yemen, a neighboring KSA country, approximately $30-53 \%$ of all stool samples sent to public health hospitals suggested IPIs. ${ }^{7}$ Documented reports from several Middle East countries reveal higher rates of IPIs among children; 31.5\% in Egypt, ${ }^{8}$ 27.6-53\% in Gaza, ${ }^{9} 26 \%$ in Tunis, ${ }^{10} 21 \%$ in Lebanon, ${ }^{11} 38.7 \%$ in Oman, ${ }^{12}$ and $34.8 \%$ in Bahrain. ${ }^{13}$

Multiple studies have indicated the presence of different intestinal parasites in numerous Saudi Arabian cities. A study conducted in Makkah estimated that the prevalence of IPI was $6.2 \%$ in $2011 .^{14}$

Bolbol et $\mathrm{al}^{15}$ stated a prevalence of $20.8 \%$ in Riyadh City, ${ }^{15}$ and Al-Eissa et $\mathrm{al}^{16}$ reported a prevalence of $21.2 \%$ in Al-Baha City, and there was no statistical discrepancy relative to more recent information. In a more recent study, Al-Braiken et $\mathrm{al}^{3}$ documented a higher prevalence $(33.8 \%)$ of IPI in the Jeddah Region, which was also higher than the prevalence observed in the Eastern province (9.3\%) reported by Qadri et al. ${ }^{17}$

Moreover, the prevalence of IPI is far lower in KSA than other countries, such as Yamoussoukro, which

Table 1 - Summary of the prevalence of intestinal parasite infection in different Saudi cities.

\begin{tabular}{lcc}
\hline City & Prevalence (\%) & Study \\
\hline Jeddah & 33.8 & Al-Braiken et al $^{3}$ \\
Al-Baha & 17.4 & Wakid et al $^{18}$ \\
& 21.2 & Al-Eissa et al $^{16}$ \\
Riyadh & 20.8 & Al-Megrin et al ${ }^{19}$ \\
Eastern province & 9.3 & Bolbol et al ${ }^{15}$ \\
Makkah & 6.2 & Qadri et al $^{17}$ \\
\hline
\end{tabular}

Disclosure. Authors have no conflict of interests, and the work was not supported or funded by any drug company.
Mathurin et $\mathrm{al}^{18}$ reported to have a prevalence of $47.4 \%$. In Morocco, the prevalence was reported to be $51 \% ;^{18}$ it was reported to be $89.6 \%$ in Argentina ${ }^{19}$ and $93 \%$ in Nicaragua. ${ }^{20}$

In contrast, Al-Megrin et $\mathrm{al}^{21}$ estimated a higher and more statistically meaningful incidence of diarrheal symptoms $(15.7 \%)$ in the infected community, which is significant relative to the non-infected population. This is consistent with recent evidence reported by Mathurin et $\mathrm{al},{ }^{18}$ Hawash et $\mathrm{al},{ }^{22}$ and Hegazi et $\mathrm{al}^{23}$ on the association between IPI and diarrheal symptoms. In the past, the diarrheal symptoms dissociated from IPI symptoms negatively affected the prevalence tracking; this can explain the prevalence difference between previous and recent studies, especially between children ranging in age from 7 months to 6 years. ${ }^{15}$

Various studies have shown that the majority of IPIs are caused by protozoa rather than intestinal worms, ${ }^{24}$ such as research conducted by Al-Megrin et al, ${ }^{21}$ which showed that approximately $95 \%$ of IPIs are caused by protozoa and approximately $5 \%$ are caused by other parasites. It has been commonly documented that Blastocystis hominis (B. hominis), Entamoeba histolytical dispar (E. histolyticaldispar) and Giardia lamblia (G. lamblia) first emerged as the most prevalent parasites triggering the majority of intestinal infections in KSA. ${ }^{4}$ In a cross-sectional study conducted in 2008 in Jeddah, KSA, the subjects were from outpatient clinics, there was a high prevalence of these parasite-induced infections, but this was not statistically significant in comparison to other gastrointestinal infection-inducing parasites. ${ }^{3}$ Amer et $\mathrm{al}^{26}$ reported on data obtained from a 5 -year retrospective survey by King Fahad Medical City, Riyadh, KSA; the study found that the most prevalent parasites in Riyadh were E. histolytica $(0.27 \%)$, Cryptosporidium sp. (0.1\%), G. lamblia $(0.07 \%)$, and Trichuris trichiura (0.03\%). According to Al-Braiken et $\mathrm{al}^{3}{ }^{3} \mathrm{~B}$. hominis was found to be prevalent in $9 \%$ of the infected cases. The latest findings indicate that a parasite is linked with some intestinal conditions and that immune responses modulate the impact, suggesting that the cause is an opportunistic parasite. ${ }^{27}$ In comparison, the occurrence of watery diarrhea has an important correlation. ${ }^{3} \mathrm{Al}-\mathrm{Braiken}$ et $\mathrm{al}^{3}$ suggested that $B$. hominis occurs periodically between parasite faunas, in line with the observation that in $6 \%$ of the cases E. histolytica has been reported for this parasite and comparable reports have also been reported for this parasite. In KSA, the prevalence range is $1.2-14 \%$ in different regions. ${ }^{28} \mathrm{In}$ 2020, Wakid ${ }^{18}$ evaluated infections of middle school boys in Jeddah, KSA finding that 46 students (17.4\%) 
were contaminated with intestinal parasites, including 7 protozoa: primarily Blastocystis spp., G. lamblia, E. histolyticaldispar and 3 parasites of helminth, including Hymenolepis nana, Ascaris lumbricoides, and Trichuris trichiura. ${ }^{18}$

In standard diagnostic laboratories, the detection of amoebiasis by microscopic recognition of stool parasites remains insensitive, since it cannot be differentiated from non-pathogenic amoeba. A number of research studies have been conducted in the Middle East to determine the prevalence of $G$. lamblia infection. ${ }^{9}$ Indeed the prevalence of $G$. lamblia in children in this analysis might indicate that there is no infection or intermittent cyst excretion, as cysts may pass at 2-3 day intervals and often at 7-8 day intervals, and sometimes the prevalence in this sample is far lower than the prevalence found for this organism in Jeddah, KSA. ${ }^{29}$ The failure to diagnose $G$. lamblia infection in children for the duration of the study can indicate that cysts are either missing or are sporadic, since cysts may pass after 2-3 days or even 7-8 days, and even repeated microscopic tests sometimes do not reveal that parasites are present in the stools in patients who have giardiasis. ${ }^{29}$

Another literature analysis indicated that Cryptosporidium infection was reported in $2.6 \%$ of Saudi infants. ${ }^{3}$ Provided that certain laboratories only test for the presence of Cryptosporidium in stools on a physician's order, cryptosporidiosis is generally undiagnosed in the field. In this study, the prevalence for Cryptosporidium infection was consistent with the findings reported in other studies from the Middle East. ${ }^{30}$ However, the prevalence of Cryptosporidium was lower (32\%) and asymptomatic (4.7\%) in 2000 in Jeddah, KSA and it was $69 \%$ in infants in the same study. The prevalence of $A$. lumbricoide diseases, along with Trichuris trichiuria, hookworm, and other worms, was found to be minimal. ${ }^{6,28} \mathrm{Al}$-Megrin et $\mathrm{al}^{19}$ reported that among preschool children in Riyadh, KSA, G. lamblia was the most prevalent parasite contributing to intestinal infections (37.8\%), followed by E. histolytica $(24.4 \%)$, then B. hominis $(20 \%)$ and Cryptosporidium parvum. A few cases were diagnosed with Cyclospora cayetanensis (4.4\%), A. lumbricoides $(2.2 \%)$, and $H$. nana $(2.2 \%)$. These findings confirm what has been mentioned in earlier reports, such as the one by Al-Eissa et $\mathrm{al}^{16}$ and the more recent one in Saudi Arabia by Al-Braiken. ${ }^{3}$ This update coincides with more recent studies from numerous locations worldwide, such as those conducted by Sharif et al ${ }^{31}$ and $\mathrm{Mbae}$ et al, ${ }^{32}$ particularly for children aged 5 years and younger. G. lamblia is the most widespread parasite contributing to intestinal infections, in accordance with other studies from Riyadh, KSA by Alkhalife, ${ }^{4}$ from Jeddah, KSA by Zakai, ${ }^{6}$ and from Al-Baha by Al-Eissa et al. ${ }^{16}$ Compared to the afore-mentioned findings, it is worth noting that this report found an increase in the prevalence rate of $G$. lamblia in Riyadh City and Jeddah City. ${ }^{3}$ Many studies from other countries in the Middle East reported that $G$. lamblia infections are the most common infections induced by protozoa in children. ${ }^{33} \mathrm{Al}-$ Megrin et $\mathrm{al}^{19}$ finding that E. histolytica is the second most prevalent parasite contributing to intestinal infection among children in Riyadh City, is compatible with the results from Al-Baha City ${ }^{16}$ and Jeddah $\mathrm{City}^{28}$ and in accordance with the findings reported by Hegazi et al. ${ }^{24}$ However, a lower prevalence was documented in Taif, a city in western Saudi Arabia, ${ }^{34}$ and in the city of Côte d'Ivoire, as reported by Mathurin et al. ${ }^{20}$ Moreover, B. hominis infections (20\%) were ranked third by Al-Megrin et al. ${ }^{19}$ This finding is comparable to the results reported in previous research that explored the prevalence of the same organism in various areas of Saudi Arabia. ${ }^{35}$ Furthermore, C. parvum was reported to have a prevalence of $8.9 \% .{ }^{19,36}$ However, that percentage is considerably less than that reported by Sanad and Al-Malki in 2007. ${ }^{37}$ They reported the prevalence of cryptosporidiosis to be $69.7 \%$ in children (69.7) younger than the age of 2 who have compromised immunity. ${ }^{37}$ Another study conducted on children of Jeddah reported that $32 \%$ of the infected cases were symptomatic and $4.7 \%$ of the cases were infected but clinically silent. ${ }^{28}$

Risk factors for IPIs and their influence on the prevalence based on different Saudi cities. The risk factors for IPIs varied. Some risk factors are behavioral, others are demographic and subjective. This section presents an overview of these risk factors.

a. Attending awareness campaigns. A survey by $\mathrm{Al}-\mathrm{Saad}$ et $\mathrm{al}^{38}$ conducted in 2018 in Jeddah, KSA reported that $92.7 \%$ of the participants did not attend awareness campaigns. A study conducted by Al-Ain in the United Arab Emirates (UAE) suggested the benefit of coordinating public awareness campaigns to disseminate information on IPI processes, signs and alert signals to reinforce the significance of receiving medical advice and to inform people regarding the measures they can take to protect themselves from contracting certain infections. ${ }^{39}$ The Emairati recommendation was presented to all 6 of the Gulf Cooperation Council (GCC) countries (Bahrain, Kuwait, Oman, Qatar, Saudi Arabia, and the UAE), which are recognized as high-income countries and have accepted community preventive medical services by $\mathrm{WHO} .{ }^{40}$ 
b. Previous history of IPIs. In their 2018 report, Al-Saad et $\mathrm{al}^{38}$ stated that the majority $(75.5 \%)$ of their participants have no history of IPIs. However, $80.9 \%$ of the signs, including abdominal discomfort, vomiting, diarrhea and nausea, were reported. A study carried out in Jeddah showed that the diagnosis of parasite infections, such as amebae, through microscopic stool detection, is insensitive. ${ }^{38}$ That study also addressed the scarcity of precise data on amoebiasis and other parasitic bowel infections. ${ }^{38}$ In 2010, a study conducted in Al-Ahssa found that there was a strong probability of infection owing to a prior history of previous IPIs among family members, contributing to a $24.5 \%$ likelihood of re-infection. ${ }^{41}$ Another study found that, in restaurants where $94 \%$ of the participants are at high risk of contracting IPIs, transmission of disease through food sources is an ongoing global problem. ${ }^{42}$

c. Health behaviors. In their 2004 study, Nematiana et $\mathrm{al}^{43}$ estimated that $80 \%$ of Tehran's population washed fruits and vegetables that had a high risk factor for IPIs before they were consumed by using detergents, salts and antiseptics thereby decreasing contamination; however, these substances do not eradicate the bacterial and parasite counts. Another cross-sectional study conducted by Gelaw et $\mathrm{al}^{44}$ in 2013 established a statistically significant correlation between hand hygiene practices and parasitic infection rates among Ethiopian primary school children, suggesting that bad hand hygiene practices substantially increased the infection rates. However, a different association has been reported in numerous Saudi studies. For example, in a 2013 study conducted in Al-Ahssa, KSA, 67.7\% of the participants had strong hand hygiene practices, but $90 \%$ still had parasitic infections. ${ }^{38}$ Moreover, a recent study conducted in Jeddah stated that hand washing with water alone was a statistically significant risk factor for IPI transmission. ${ }^{45}$

d. Food and water sources. Many studies researched the role of the water and food supply in many countries including KSA. ${ }^{46}$ Food servers, such as chefs, can be a major cause of infection if they are sick. They may be a direct source of illness, or they can also be a silent carrier that transfers the parasite, and thus the disease, to someone later. ${ }^{42}$ In Al-Ahssa in 2018, $95 \%$ of the population under investigation reported having frequently dined in restaurants, putting them in direct danger of experiencing this threat. ${ }^{38}$ Furthermore, the community's source of drinking water was proposed to be a major factor in predicting the parasite infection. ${ }^{38}$ Al-Saad et al $^{38}$ suggested that approximately $34.5 \%$ of the subjects in their study in Jeddah that used water from tanks were at a greater risk of multiple parasitic infections. Moreover, farm animals are considered to be a major component of the transmission chain of numerous diseases, ${ }^{47}$ which represents a severe challenge to public health. ${ }^{48}$ However, in an Al-Ahssa study of 500 people in 2008, 33.8\% of whom tested positive for parasitic infections, nearly $85.5 \%$ of the participants reported a lack of direct contact with livestock, which was expected to reduce their chance to developing a parasitic gastrointestinal tract infection. ${ }^{38}$

e. Age. School-aged children were shown to have a significant predictive effect on intestinal parasite infections; they were more likely to be infected than children that do not attend schools. Minor children usually play in open fields, and the result may clarify their own mouth. ${ }^{49}$ There is a clear correlation between intestinal parasite infection, particularly G. lamblia, and diarrhea in pre-school-age children in Riyadh, KSA in comparison to infants. ${ }^{14}$ In contrast, the same research in Riyadh, KSA, showed that children between the ages of 3 and 5 tend to have the highest rate of infections $(23.3 \%)$ relative to other experimental categories. In 2018, Gebretsadik et al ${ }^{50}$ reported the same average for this age group. This result supports what Ghiwot et $\mathrm{al}^{51}$ suggested in 2014 in that children that are 4 years of age are the typical age group with the highest frequency rate of infection. However, Wongstitwilairoong et $\mathrm{al}^{52}$ reported the highest prevalence rate for children between the ages of 2 and 3, which was slightly lower than the average median prevalence age in other studies.

f. Gender. It is stated in the literature that genderassociated disparities in susceptibility to parasites and the effect of testosterone (T) on immunosuppression make women more susceptible to parasite infections. ${ }^{53}$ This paradigm indicates that, in reaction to parasites, sexual dimorphism is largely controlled by the host's immune system, which fails to recognise that such parasites may clearly respond to their female and male hosts' distinct sex steroidal hormone profiles. ${ }^{54}$ Hypothesizing that women are more immune to parasites than men, causing prudent simplification precautions, has been considered the 'feminine dominant theory' in practice for over half a century. This hypothesis confirms that the increased mortality rate in human males relative to females is due to their susceptibility to infectious agents. ${ }^{55}$ Women's relative resistance to infection was correlated with discrepancies between sex life history, including mates, social hierarchy, ${ }^{53}$ sexual activity and resource spending to establish a reproductive parasite immune response. ${ }^{56}$ Immune responses in males and females are triggered by microbes and are mostly attributable to ligand-specific receptors in or within the immune cell bioplasm. ${ }^{57}$ 
While sexual steroids hormones have a consistent effect on immune cell functioning, these gender differences are highly prevalent and they depend on the parasite-host framework. Although gamma interferon (IFN-g) concentrations are higher in female mice than male mice in malaria infection, ${ }^{58}$ female mice produce less IFN-g and tumor necrosis factor alpha (TNF- $\alpha$ ) than male mice in reaction to Toxoplasma gondii. ${ }^{53}$ In Taenia crassiceps, a parasite with a higher IFN-g response in females than males, females have a higher interleukin 10 (IL-10) response than females with IL-6 and IL-12.53

In this case, females have a lower IFN-g response than males. In hamsters, males develop deeper lesions after infection with Leishmania panamensis. ${ }^{59}$ Male hamsters also have higher IL-4, IL-10 and transforming growth factor beta (TGF- $\beta$ ) concentrations than female hamsters, but levels of IL-12 and IFN-g are not different based on gender. ${ }^{53}$

In a study on the incidence of IPI among classes of adolescents, including pre-school boys and girls (below 6 years), the prevalence was found to be approximately $20.4 \%$ in boys and approximately $15.9 \%$ in girls, suggesting no statistically relevant difference between the genders $(p>0.05) .{ }^{19}$ This finding is consistent with the results reported in a study from Thailand, ${ }^{52}$ which showed a prevalence of $18.5 \%$ for boys and $16.1 \%$ for girls, a study in Italy, where $17.1 \%$ of the boys and $12.1 \%$ of the girls were infected ${ }^{60}$ and in a study in Morocco where $63.5 \%$ of the boys and $60.4 \%$ of the girls were infected. ${ }^{61}$ These findings disagreed with the results reported in previous research indicating reversed incidence rates from Nepal, where the percentages were approximately $16.9 \%$ for boys and $22 \%$ for girls, ${ }^{62}$ and Ethiopia, where $32.1 \%$ of the boys and $35.9 \%$ of the girls displayed IPI features attributable to protozoal infection. ${ }^{44}$

g. Immune status. In 2010, the incidence of IPIs among immune-compromised children in Riyadh, KSA, was nearly double that of previous studies conducted in Riyadh City during the same decade. ${ }^{63}$ Immune status is widely thought to play a significant role in determining if an individual may contract a parasitic infection. Moreover, Frank's key publication on immunity and parasite infestation claimed that IL play a significant role as a parasite infection prognostic factor. ${ }^{64}$ They especially found that IL-4 improved the prognosis and probability of complete recovery of cutaneous leishmaniasis, and higher levels of IL-10 and interferon gamma improved the prognosis and probability of recovery in visceral leishmaniasis. They linked immunoglobulin $\mathrm{E}$ and eosinophilic behaviors with schistosomiasis infection defence. That also includes basophils and IL-4. ${ }^{64}$ Furthermore, parasitic infections were associated with intestinal immunological conditions, such as irritable bowel disorder and irritable bowel syndrome; ${ }^{65}$ the incidence of blastocystis is $67 \%$ in individuals with irritable bowel syndrome. They also observed a higher incidence of increased intestinal mucosa thickness after infection with Giardia species. ${ }^{65}$ The precise mechanism behind these changes and the various associated implications is not yet understood.

However, according to Mohammadi et al, ${ }^{65}$ several parasite infections interfere with the production of differentiation clusters, which play a major role in modulating and mediating a positive, balanced immune response.

h. Socio-economic status. According to WHO, socio-economic status has been recognized as one of the determinants of health that has an impact not only on the state of an individual's health, but also the type of disease that he/she is likely to develop; ${ }^{66}$ thus, better control over parasitic infections is an essential determinant of health. Furthermore, some socio-economic factors subject people to diverse health inequalities. ${ }^{67}$ There are various ways in which socioeconomic levels in KSA could influence IPIs. For example, the educational background of parents has been reported to impact the prevalence of parasitic infections. In Riyadh, KSA, it was observed that cases of children with a higher prevalence of IPIs were correlated with families with lower education levels, suggesting a higher probability of infection in these children in comparison to those whose parents had higher education levels. ${ }^{68}$ Furthermore, mothers' working status in Riyadh, KSA has also been recognized as a risk factor.

It is worth noting that, during this period, with the steady increase in the number of women employed at home with subsequent economic development, more housekeepers are being imported primarily from Asian countries, such as Indonesia, Bangladesh, India and Sri Lanka, and these workers are becoming increasingly important, offering valuable insight into the source and handling of household infections. ${ }^{69}$ This process also triggers the importation of endogenous pathogens from their home country to KSA to reshape the public health of the country. ${ }^{70}$ In Abha, KSA it was reported that $46.5 \%$ of the homes with Asian female housekeepers had at least one parasitic infection. ${ }^{69}$ In comparison, low-income households and families listed as being poor were more likely to have children with IPIs (42.1\%). ${ }^{71}$ Moreover, an increase in the prevalence of IPIs was found in places where humans reside near animals. It was apparent when 2 groups of households living in 2 different areas of southern Riyadh, KSA 
screened positive for intestinal parasitosis (19.1\% prevalence). ${ }^{19}$ However, in households in northern Riyadh, KSA, the prevalence was approximately $14.9 \%$. Although the difference was not substantial, it confirms what Masoumeh et $\mathrm{a}^{33}$ indicated in their 2012 study from Iran, which is that economic status and living area affect the occurrence of parasite infections. However, according to Hawash et al, ${ }^{72}$ infections could be more frequent in urban populations $(76.2 \%)$ in comparison to rural communities (23.8\%).

In conclusion, intestinal parasitic infection is a main type of chronic disease in KSA with several acute presentations. The risk factors associated with IPI have differing incidence rates in various areas of KSA. One of the risk factors, age, has a higher prevalence in younger people with a lower immune response, particularly children under the age of 5 . Some organisms are more abundant in KSA than others; for example, $B$ homini, $E$. histolyticaldispar, and G. lamblia are the most common parasites in KSA, representing the most parasitic infections from protozoa and non-worm infections. Boys are believed to be at higher risk than girls; however, more recent publications indicate a lower gender gap, thus, not reflecting a major differential. Moreover, while numerous reports have found that girls are at higher risk than boys for contracting parasitic infections, the differences between the genders are not statistically significant. Another aspect is having access to advertisements and health education/awareness programs. These programs are not yet sufficient to create a tangible degree of knowledge in the community. Additionally, health behavior remains a powerful risk factor, and it is not denied that people in KSA still engage in extensive unsafe behaviors that require urgent public health action. Among the people recently infected with parasites, the incidence of new infections has decreased. In contrast, communities in which the water is supplied from a lake and communities without direct access to clean water have much higher parasitic infection rates.

Socio-economic status is a major risk load. Low-income residents per capita had poorer access to health promotion services, leaving them more susceptible to infection. Higher-economic communities tend to employ migrant housekeepers from other countries that have different protozoa and parasites, which, in many cases, increase the incidence of infection. Moreover, food prepared in restaurants is often more vulnerable to these pathogens than food that is made at home.

Acknowledgment. The author gratefully acknowledge Scribendi (www.scribendi.com) for English language editing.

\section{References}

1. Torgerson PR, Devleesschauwer B, Praet N, Willingham, AL, Kasuga, F, Rokni MB, et al. world health organization estimates of the global and regional disease burden of 11 foodborne parasitic diseases, 2010: a data synthesis. PLoS Med 2015; 12 : e1001920.

2. Dorny P, Praet N, Deckers N, Gabriel S. Emerging food-borne parasites. Vet Parasitol 2009; 163: 196-206.

3. Al-Braiken FA. Is intestinal parasitic infection still a public health concern among Saudi children? Saudi Med J 2008; 29: 1630-1635.

4. Alkhalife IS. Retrospective analysis of intestinal parasitic infections diagnosed at a University Hospital in Central, Saudi Arabia. Saudi Med J 2006; 27: 1714-1718.

5. Ihejirika OC, Nwaorgu OC, Ebirim CI, Nwokeji CM. Effects of intestinal parasitic infections on nutritional status of primary children in Imo State Nigeria. Pan Afr Med J 2019; 33: 34.

6. Zakai HA. Intestinal parasitic infections among primary school children in Jeddah, Saudi Arabia. J Egypt Soc Parasitol 2004; 34: 783-790.

7. Azazy AA, Raja’a YA. Malaria and intestinal parasitosis among children presenting to the Pediatric Centre in Sana'a, Yemen. La Revue de Santé de la Méditerranée Orientale 2003; 9: 1048-1053.

8. Youssef AI, Uga S. Review of parasitic zoonoses in Egypt. Trop Med Health 2014; 42: 3-14.

9. Al-Hindi A, Shubair ME, Marshall I, Ashford RW, Shareif FA, Abed AA. et al. Entamoeba histolytica or Entamoeba dispar among children in Gaza, Gaza Strip? J Egypt Soc Parasitol 2005; 35: 59-68.

10. Jemli M, Sabbahi S, Ayed L Ben. Performance of urban wastewater treatment of four activate sludge treatment plants in Tunisia. Int J Wastewater Treat 2015; 1: 1-4.

11. Araj GF, Musharrafieh UM, Haydar A, Ghawi A, Itani R, Saliba $\mathrm{R}$, et al. Trends and prevalence of intestinal parasites at a tertiary care center in Lebanon over a decade. J Med Liban 2011; 59: 143-148.

12. Patel PK, Khandekar R. Intestinal parasitic infections among school children of the Dhahira Region of Oman. Saudi Med J 2006; 27: 627-632.

13. Mukhtar A. Intestinal parasites in the state of Bahrain. Indian $J$ Pathol Microbiol 1995; 38: 341-344.

14. Zaglool DAM, Khodari YAW, Gazzaz ZJ, Dhafar KO, Shaker HA, Main UF, et al. Prevalence of intestinal parasites among patients of Al-Noor specialist hospital, Makkah, Saudi Arabia. Oman Med J 2011; 26: 182-185.

15. Bolbol AS, Mostafa SD, al-Sekait M, Al-Nasser AA. Pattern of intestinal parasitic infection in preschool children in Riyadh, Saudi Arabia. J Hyg Epidemiol Microbiol Immunol 1989; 33: 253-259.

16. Al-Eissa YA, Assuhaimi SA, Abdullah AMA, AboBakr AM, Al-Husain MA, Al-Nasser MN, et al. Prevalence of intestinal parasites in Saudi children: A community-based study. J Trop Pediatr 1995; 41: 47-49.

17. Qadri MH, Ai-Gamdi MA, Al-Harfi RA. Asymptomatic salmonella, Shigella and intestinal parasites among primary school children in the eastern province. J Family Community Med 1995; 2: 36-40.

18. Wakid MH. Intestinal parasitic infection among middle school boy students in Jeddah, Saudi Arabia. PUJ 2020; 13: 46-51. 
19. Al-Megrin WAI. Assessment the prevalence of intestinal parasites and associated risk factors among preschool children in Riyadh, Saudi Arabia. Res J Parasitol 2015; 10: 31-41.

20. Koffi M, N Djeti M, Konan T, Dje Y. Molecular characterization of intestinal protozoan parasites from children facing diarrheal disease and associated risk factors in Yamoussoukro, Cte dIvoire. African J Environ Sci Technol 2014; 8: 178-184.

21. Gamboa MI, Giambelluca LA, Navone GT. Spatial distribution of intestinal parasites in La Plata, capital of the province of Buenos Aires, Argentina. Medicina 2014; 74: 363-370.

22. Muñoz-Antoli C, Pavón A, Marcilla A, Toledo R, Esteban JG. Prevalence and risk factors related to intestinal parasites among children in Department of Rio San Juan, Nicaragua. Trans $R$ Soc Trop Med Hyg 2014; 108: 774-782.

23. Hawash YA, Ismail KA, Almehmadi M. High frequency of enteric protozoan, viral, and bacterial potential pathogens in community-acquired acute diarrheal episodes: Evidence based on results of Luminex gastrointestinal pathogen panel assay. Korean J Parasitol 2017; 55: 513-521.

24. Hegazi MA, Patel TA, El-Deek BS. Prevalence and characters of Entamoeba histolytica infection in Saudi infants and children admitted with diarrhea at 2 main hospitals at south Jeddah: A re-emerging serious infection with unusual presentation. Brazilian J Infect Dis 2013; 17: 32-40.

25. Ashtiani MTH, Monajemzadeh M, Saghi B, Shams S, Mortazavi SH, Khaki S, et al. Prevalence of intestinal parasites among children referred to Children's Medical Center during 18 years (1991-2008), Tehran, Iran. Ann Trop Med Parasitol 2011; 105: 507-513.

26. Amer OSO, Al-Malki ES, Waly MI, AlAgeel A, Lubbad MY. Prevalence of intestinal parasitic infections among patients of King Fahd Medical City in Riyadh region, Saudi Arabia: a 5-year retrospective study. J Parasitol Res 2018; 2018: 8076274.

27. Lee JD, Wang JJ, Chung LY, Chang EE, Lai LC, Chen ER, et al. A survey on the intestinal parasites of the school children in Kaohsiung county. Kaohsiung J Med Sci 2000; 16: 452-458.

28. Al-Braiken FA, Amin A, Beeching NJ, Hommel M, Hart CA. Detection of Cryptosporidium amongst diarrhoeic and asymptomatic children in Jeddah, Saudi Arabia. Ann Trop Med Parasitol 2003; 97: 505-510.

29. Al-Harthi S, Jamjoom M. Enteroparasitic occurrence in stools from residents in Southwestern region of Saudi Arabia before and during Umrah season. Saudi Med J 2007; 28: 386-989.

30. Nimri LF. Cyclospora cayetanensis and other intestinal parasites associated with diarrhea in a rural area of Jordan. Int Microbiol 2003; 6: 131-135.

31. Sharif M, Daryani A, Asgarian F, Nasrolahi M. Intestinal parasitic infections among intellectual disability children in rehabilitation centers of northern Iran. Res Dev Disabil 2010; 31: 924-928.

32. Mbae CK, Nokes DJ, Mulinge E, Nyambura J, Waruru A, Kariuki S. Intestinal parasitic infections in children presenting with diarrhea in outpatient and inpatient settings in an informal settlement of Nairobi, Kenya. BMC Infect Dis 2013; 13: 243.

33. Masoumeh R, Farideh T, Mitra S, Heshmatollah T. Intestinal parasitic infection among school children in Golestan province, Iran. Pakistan J Biol Sci 2012; 15: 1119-1125.

34. Almalki S. Factors associated with high prevalence of Entamaeba histolyticaldispar infection among children in Jeddah. AmericanEurasian J Agric \& Environ Sci 2014; 14: 50-56.
35. Dogan N, Oz Y, Koçman NU, Nursal AF. Comparison of individual differences in the direct microscopic examination in the diagnosis of intestinal parasites. Turkiye Parazitol Derg 2012; 36: 211-214.

36. Yilmaz H, Tas-Cengiz Z, Cicek M. Investigation of cryptosporidiosis by enzyme-linked immunosorbent assay and microscopy in children with diarrhea. Saudi Med J 2008; 29: 526-529.

37. Sanad MM, Al-Malki JS. Cryptosporidiosis among immunocompromised patients in Saudi Arabia. J Egypt Soc Parasitol 2007; 37: 765-774.

38. Al-Saad S, Al-Jadidi J, Al-Sulaiman N. Potential risk factors of intestinal parasitic infection in AlAhssa, Saudi Arabia. Egypt J Hosp Med 2018; 72: 3721.

39. Al-Rifai RH, Loney T, Sheek-Hussein M, Zoughbor S, Ajab $S$, Olanda $M$, et al. Prevalence of, and factors associated with intestinal parasites in multinational expatriate workers in $\mathrm{Al} \mathrm{Ain}$ City, United Arab Emirates: An occupational cross-sectional study. J Immigr Minor Heal 2020; 22: 359-374.

40. Qazi S, Aboubaker S, MacLean R, Fontaine O, Mantel C, Goodman T, Young M, Henderson P, Cherian T. Ending preventable child deaths from pneumonia and diarrhea by 2025. Development of the integrated global action plan for the prevention and control of pneumonia and diarrhea. Arch Dis Child 2015; 100: S23-S28.

41. Al-Mohammed HI, Amin TT, Aboulmagd E, Abdulmagd Elsayed, Hablus HR, Zaza BO. Prevalence of intestinal parasitic infections and its relationship with socio-demographics and hygienic habits among male primary school children in Al-Ahsa, Saudi Arabia. Asian Pac J Trop Med 2010; 3: 906-912.

42. Andargie G, Kassu A, Moges F, Tiruneh M, Hurusy K. Prevalence of bacteria and intestinal parasites among foodhandlers in Gondar Town, Northwest Ethiopia. J Heal Popul Nutr 2008; 26: 451-455.

43. Nematian J, Nematian E, Gholamrezanezhad A, et al. Prevalence of intestinal parasitic infections and their relation with socioeconomic factors and hygienic habits in Tehran primary school students. Acta Trop 2004; 92: 179-186.

44. Gelaw A, Anagaw B, Nigussie B, et al. Prevalence of intestinal parasitic infections and risk factors among schoolchildren at the University of Gondar Community School, Northwest Ethiopia: A cross-sectional study. BMC Public Health 2013; 13: 304.

45. Bakarman MA, Hegazi MA, Butt NS. Prevalence, characteristics, risk factors, and impact of intestinal parasitic infections on school children in Jeddah. J Epidemiol Glob Health 2019; 9: 81-87.

46. Balarak D, Modrek MJ, Bazrafshan E, Ansari H, Mostafapour FK. Prevalence of intestinal parasitic infection among food handlers in Northwest Iran. J Parasitol Res 2016; 2016: 8461965 .

47. Ortiz-Rodríguez MP, Ramírez-Nieto GC, Villamil-Jiménez LC. The role of animal reservoirs in social-environmental landscapes: remarks on the control of avian influenza and preparedness for pandemics. Rev Sci Tech 2016; 35: 835-843.

48. World Health Organization. [Updated 2017 May 2. Accessed 2021 January 20]. Diarrhoeal disease, Available from: https:// www.who.int/news-room/fact-sheets/detail/diarrhoeal-disease

49. Dessie A, Gebrehiwot TG, Kiros B, Wami SD, Chercos DH. Intestinal parasitic infections and determinant factors among school-age children in Ethiopia: A cross-sectional study. BMC Res Notes 2019; 12: 777. 
50. Gebretsadik D, Metaferia Y, Seid A, Fenta GM, Gedefie A. Prevalence of intestinal parasitic infection among children under 5 years of age at Dessie Referral Hospital: cross sectional study. BMC Res Notes 2018; 11: 771.

51. Ghiwot Y, Degarege A, Erko B. Prevalence of intestinal parasitic infections among children under five years of age with emphasis on schistosoma mansoni in Wonji Shoa sugar estate, Ethiopia. PLoS One 2014; 9: e109793.

52. Wongstitwilairoong B, Srijan A, Serichantalergs O, Fukuda CD, McDaniel P, Bodhidatta L, et al. Intestinal parasitic infections among pre-school children in Sangkhlaburi, Thailand. Am J Trop Med Hyg 2007; 76: 345-350.

53. Escobedo G, De León-Nava MA, Morales-Montor J. Sex differences in parasitic infections: Beyond the dogma of femalebiased resistance. In: Klein S, Roberts C, editors. Sex Hormones and Immunity to Infection. Berlin (Heidelberg): Springer; 2010. p. 187-204.

54. Escobedo G, Roberts CW, Carrero JC, Morales-Montor J. Parasite regulation by host hormones: an old mechanism of host exploitation? Trends Parasitol 2005; 21: 588-593.

55. Moore SL, Wilson K. Parasites as a viability cost of sexual selection in naturalpopulations of mammals. Science 2002; 297: 2015-2018.

56. Hanssen SA, Folstad I, Erikstad KE. Reduced immunocompetence and cost of reproduction in common eiders. Oecologia 2003; 136: 457-464.

57. Benten WPM, Becker A, Schmitt-Wrede HP, Wunderlich F. Developmental regulation of intracellular and surface androgen receptors in T cells. Steroids 2002; 67: 925-931.

58. Cernetich A, Garver LS, Jedlicka AE, Klein PW, Kumar N, Scott AL. Involvement of gonadal steroids and gamma interferon in sex differences in response to blood-stage malaria infection. Infect Immun 2006; 74: 3190-3203.

59. Travi BL, Osorio Y, Melby PC, Chandrasekar B, Arteaga L, Saravia NG. Gender is a major determinant of the clinical evolution and immune response in hamsters infected with Leishmania spp. Infect Immun 2002; 70: 2288-2296.

60. Manganelli L, Berrilli F, Di Cave D, Ercoli L, Capelli G, Otranto D. Intestinal parasite infections in immigrant children in the city of Rome, related risk factors and possible impact on nutritional status. Parasites Vectors 2012; 5: 265.

61. El Fatni C, Olmo F, El Fatni H, Romero D, Rosales MJ. First genotyping of Giardia duodenalis and prevalence of enteroparasites in children from Tetouan (Morocco). Parasite 2014; $21: 48$.
62. Mukhiya RK, Rai SK, Prajapati A. Intestinal protozoan parasitic infection among school children. J Nepal Health Res Counc 2012; 10: 204: 7 .

63. Al-Megrin WAI. Intestinal Parasites Infection among Immunocompromised patients in Riyadh, Saudi Arabia. Pakistan J Biol Sci 2010; 13: 390-394.

64. Delves PJ, Roitt I. Encyclopedia of Immunology Science Direct. 2nd ed. United Kingdom; Academic Press: 1998.

65. Mohammadi R, Hosseini-Safa A, Ehsani Ardakani MJ, RostamiNejad M. The relationship between intestinal parasites and some immune-mediated intestinal conditions. Gastroenterol Hepatol Bed Bench 2015; 8: 123-131.

66. Torgerson PR. One world health: Socioeconomic burden and parasitic disease control priorities. Vet Parasitol 2013; 195: 223-232.

67. Walters S, Suhrcke M. Socieoeconomic ineualities in health nd health care access in central and eastern Europe and the CIS: a review of the recent literature. [Updated 2005. Accessed 2021 January 20]. Available from: https://pubmed.ncbi.nlm.nih. gov/25926937/

68. Abossie A, Seid M. Assessment of the prevalence of intestinal parasitosis and associated risk factors among primary school children in Chencha town, Southern Ethiopia. BMC Public Health 2014; 14: 166.

69. Al-Madani AA, Mahfouz AA. Prevalence of intestinal parasitic infections among Asian female house keepers in Abha District, Saudi Arabia. Southeast Asian J Trop Med Public Health 1995; 26: 135-137.

70. Lander RL, Lander AG, Houghton L, William, SM, CostaRibeiro H, Barreto DL. Factors influencing growth and intestinal parasitic infections in preschoolers attending philanthropic daycare centers in Salvador, Northeast Region of Brazil. Cad Saúde Publica 2012; 28: 2177-2188. 71.

Nobre LN, Silva R V, Macedo MS, et al. Risk factors for intestinal parasitic infections in preschoolers in a low socioeconomic area, Diamantina, Brazil. Pathog Glob Health 2013; 107: 103-106.

72. Hawash YA, Dorgham LS, Amir EAM, Sharaf OF. Prevalence of intestinal protozoa among Saudi patients with chronic renal failure: a case-control study. J Trop Med 2015; 2015: 563478. 